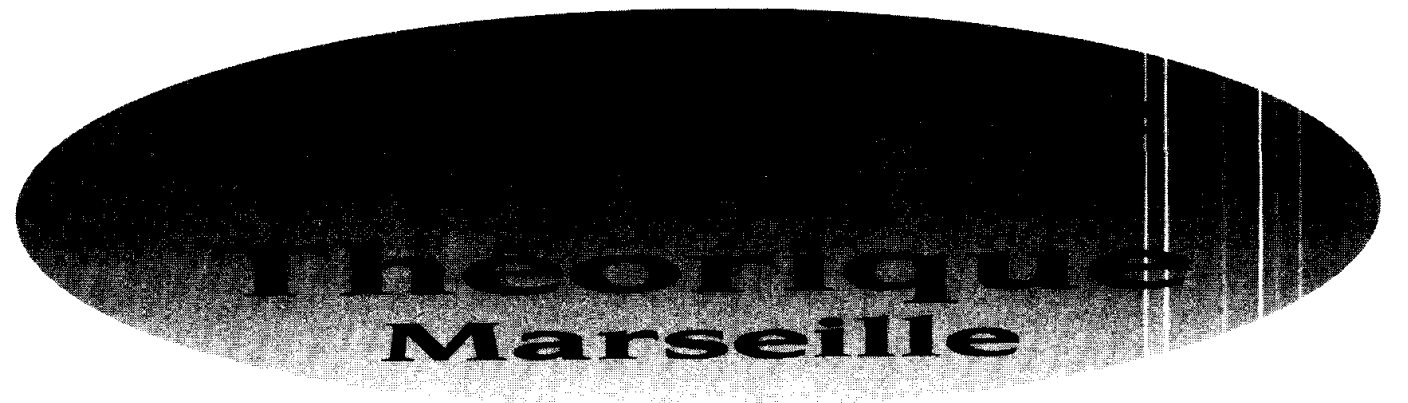

\title{
Damping of spin waves for doped antiferromagnet
}

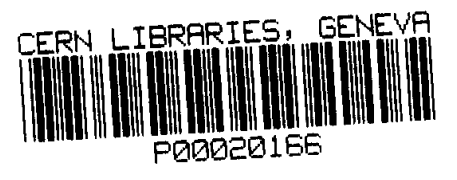

\author{
A. Belkasri*and J.L. Richard
}

\begin{abstract}
The spin-wave energy, the damping and the staggered magnetization are calculated for a lightly doped antiferromagnet in the framework of the $t-J$ model. The Dyson's equation for the dynamical spin susceptibility is derived and studied at zero temperature. It is shown that the staggered magnetization as well as the spin-wave velocity vanish for some critical hole concentration. The damping of spin waves is computed and found to be very sensitive to the hole doping. The results are in good agreement with experimental data of $\mathrm{YBa}_{2} \mathrm{Cu}_{3} \mathrm{O}_{6+x}$.
\end{abstract}

October 1993

CPT-93/P.2955

*and Université d'Aix-Marseille II 

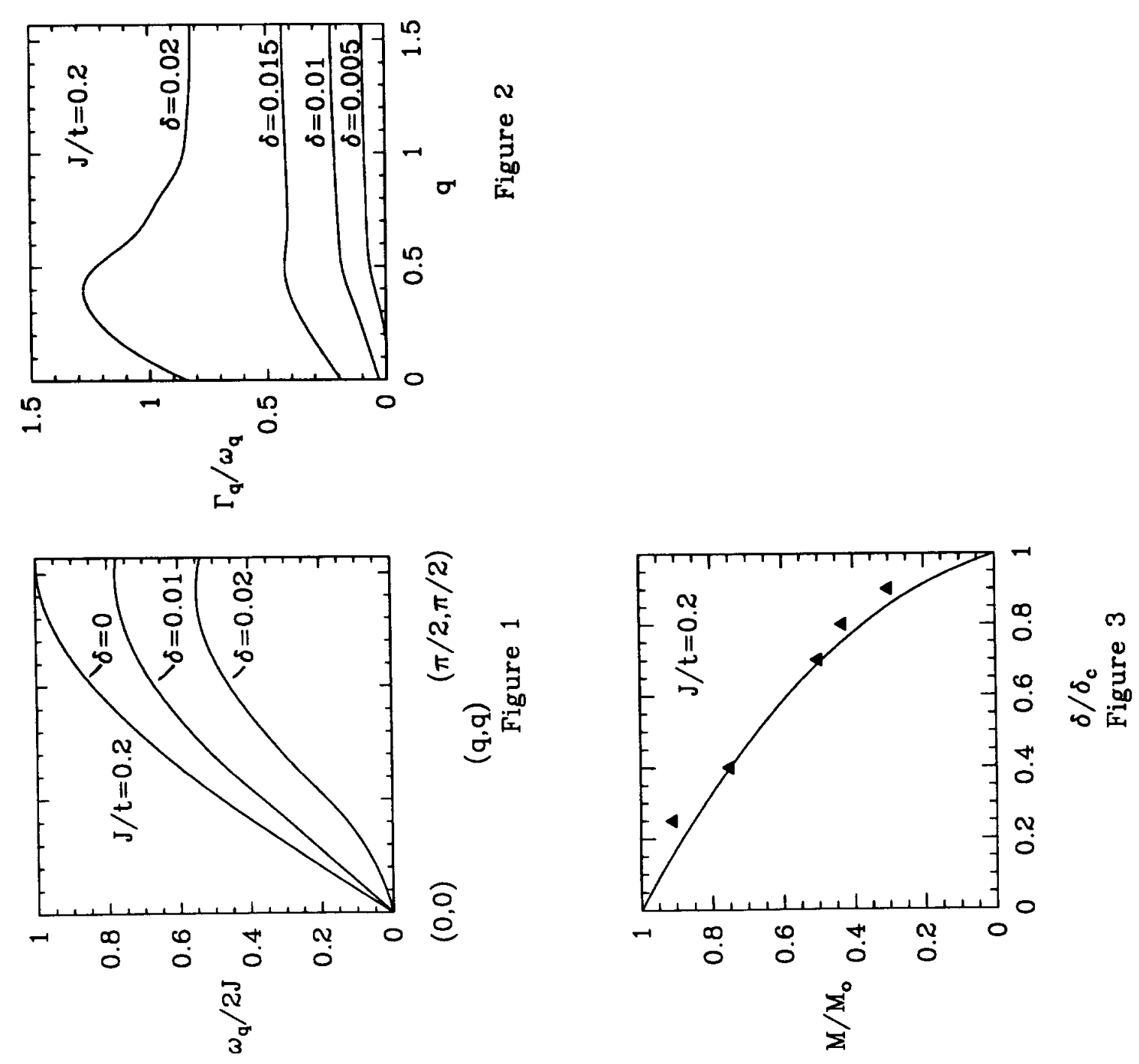
. 


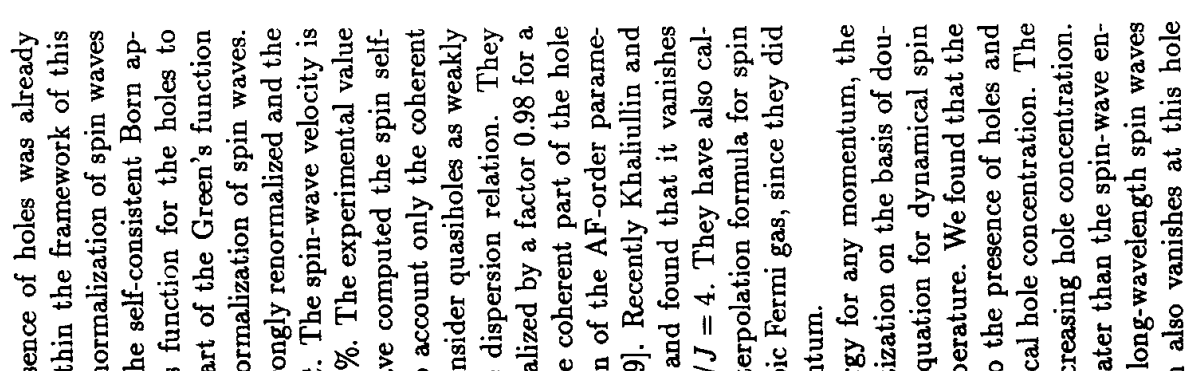

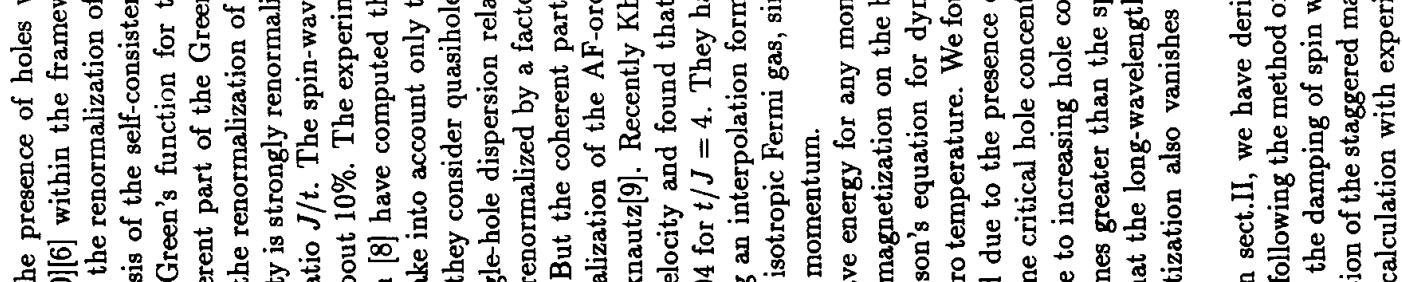

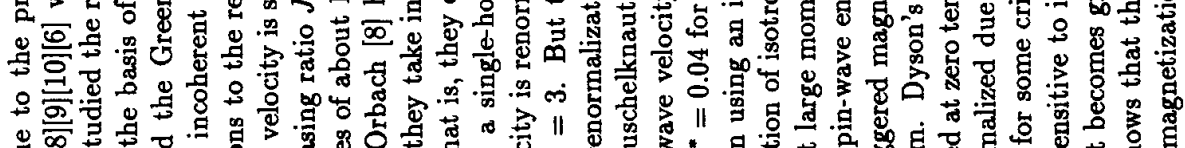

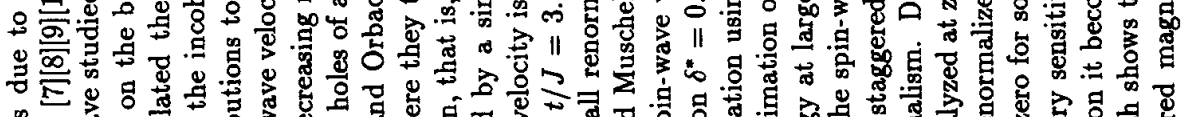

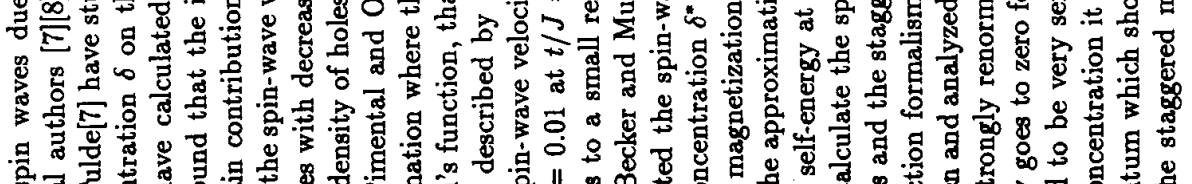

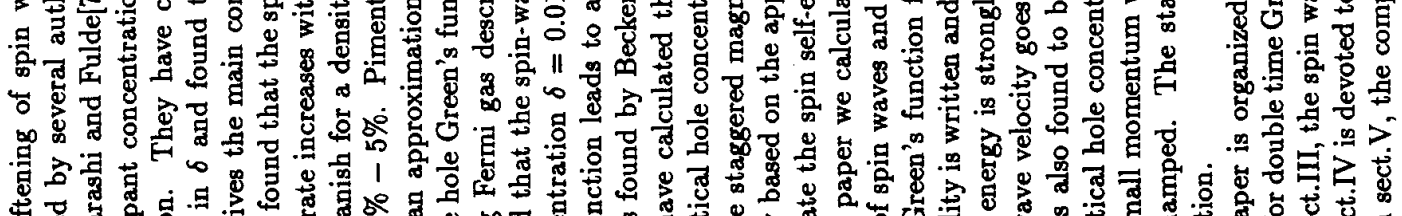

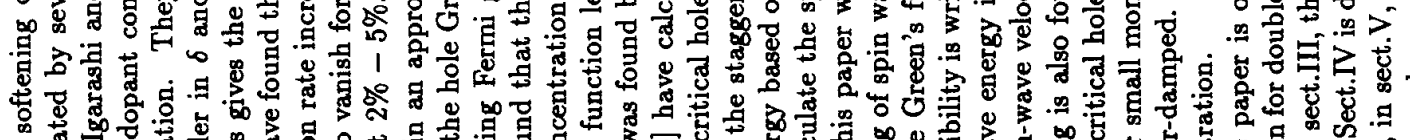

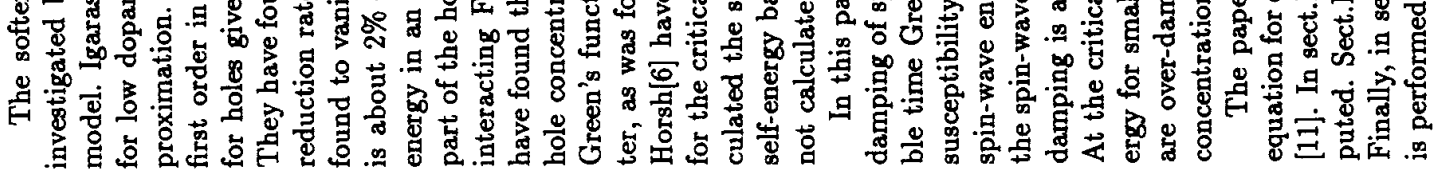

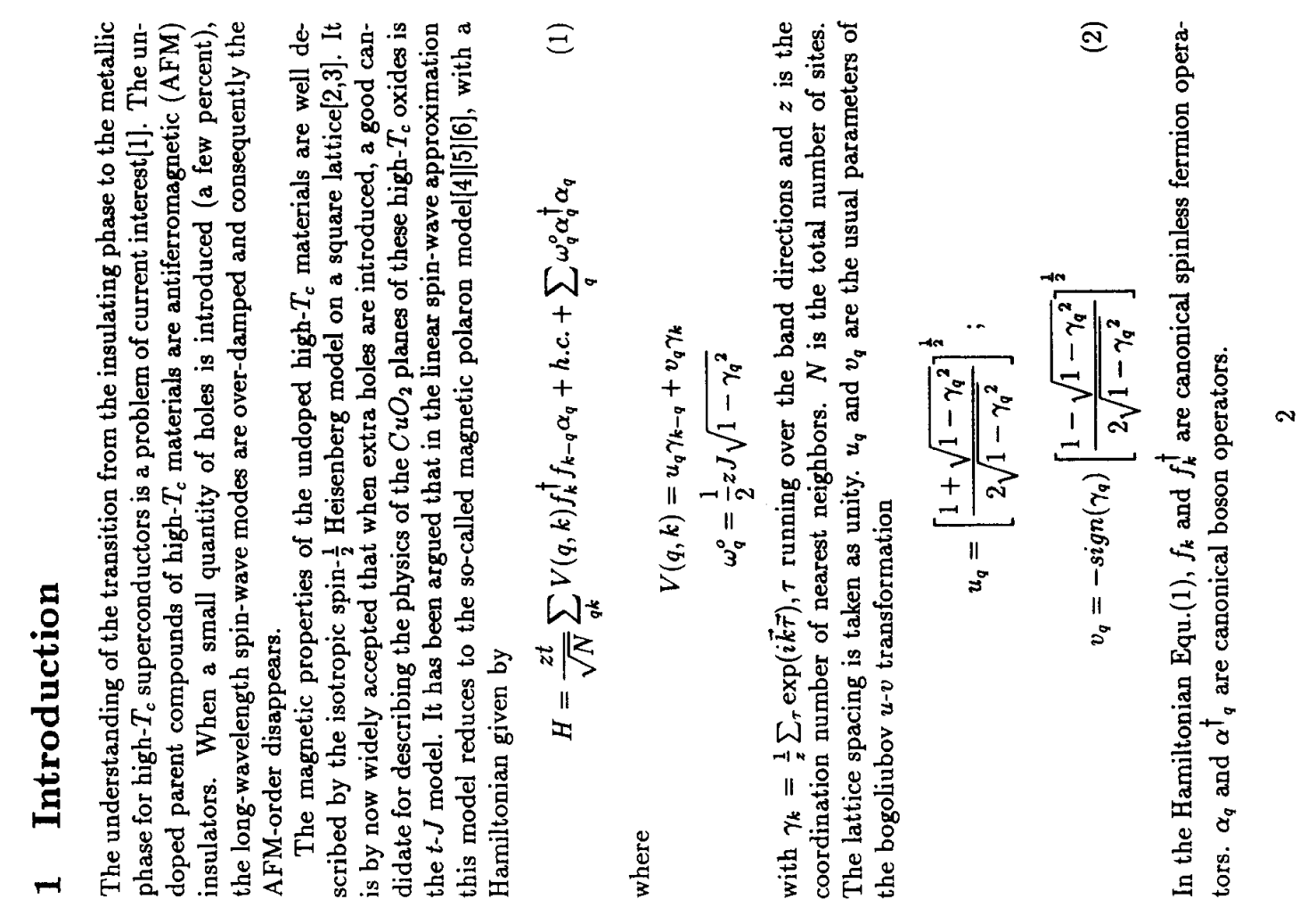




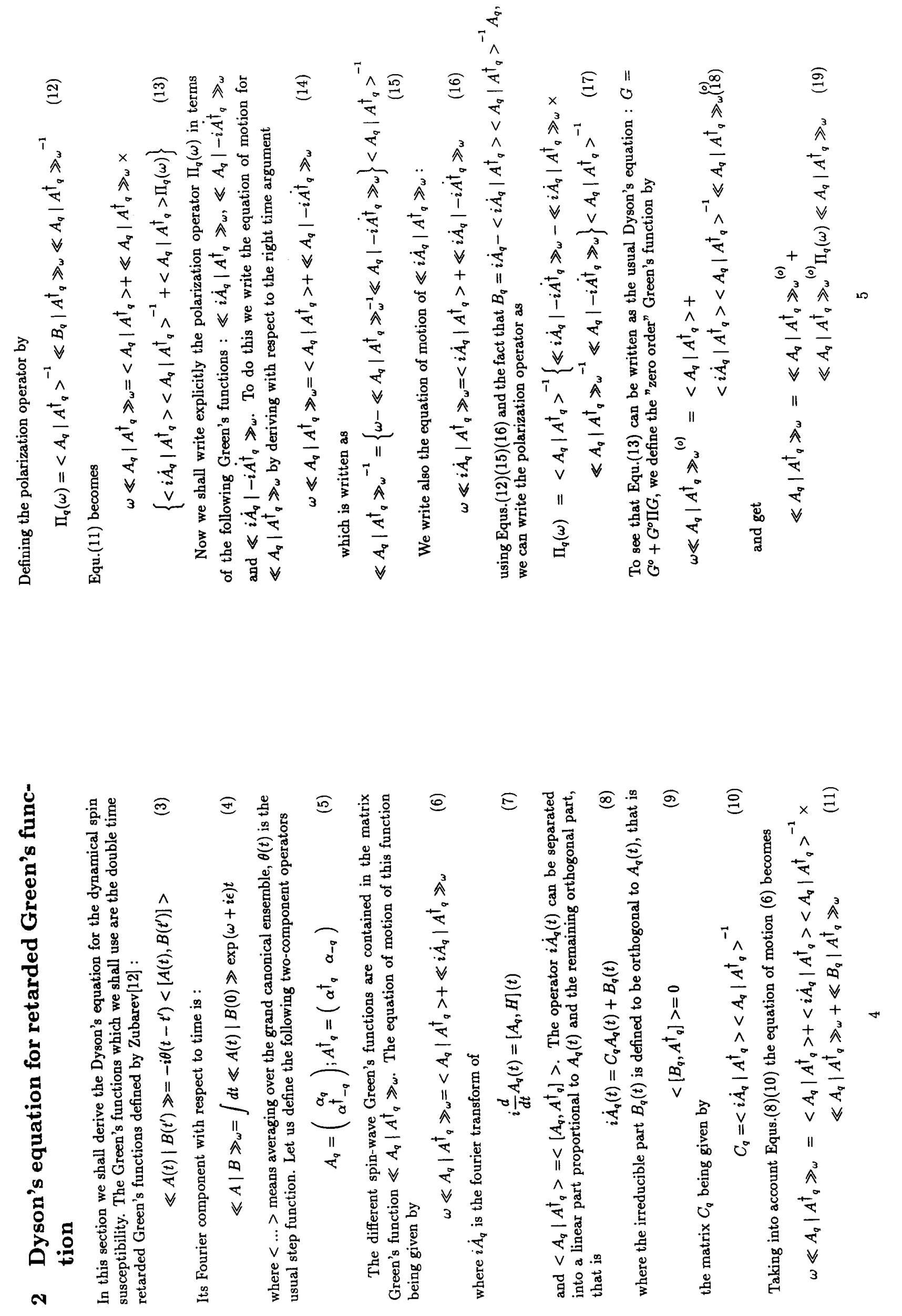



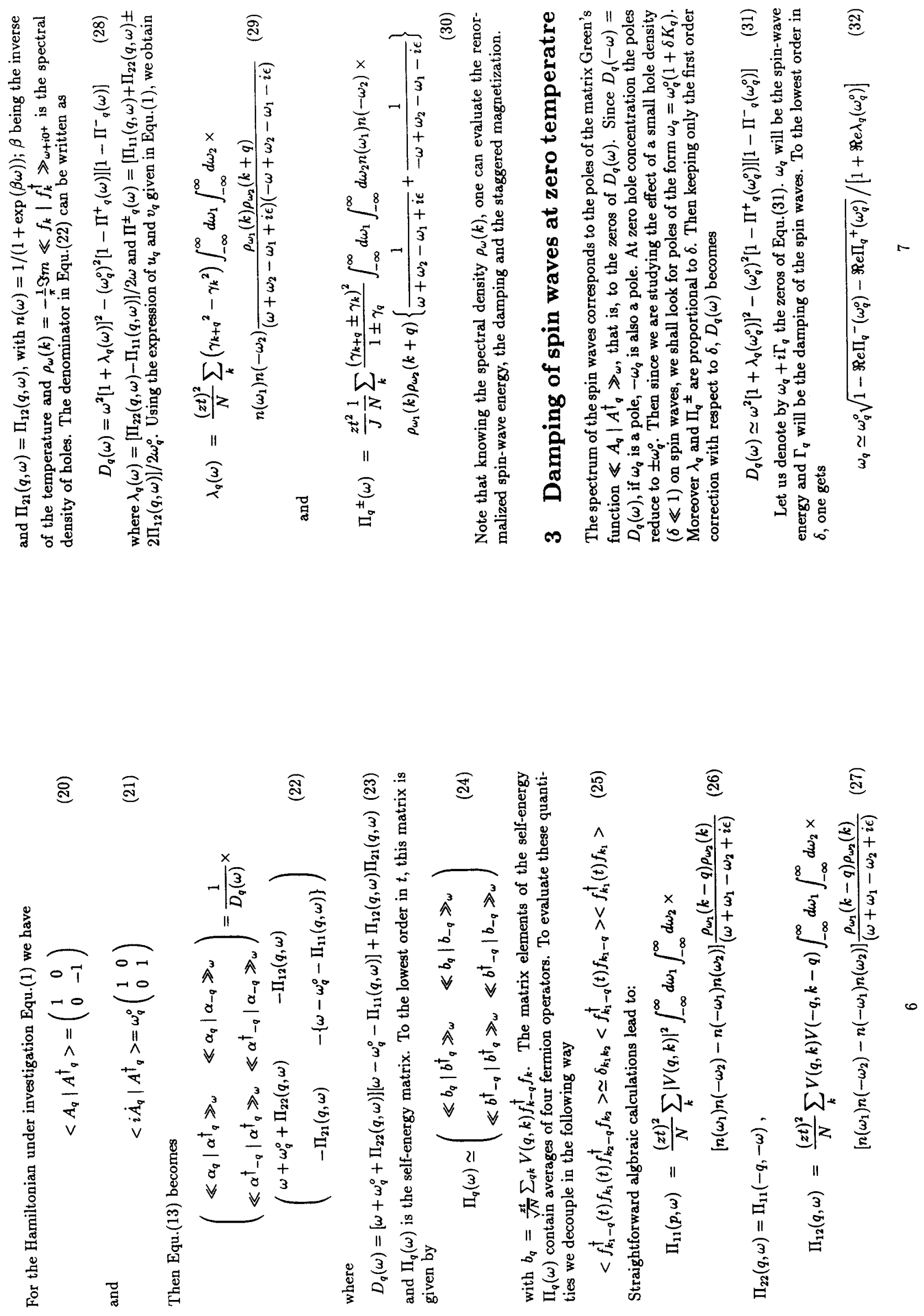


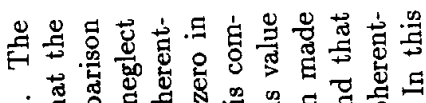

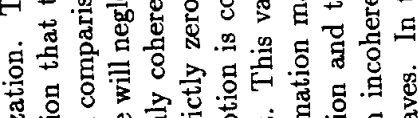

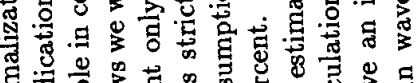

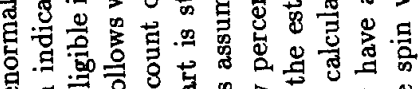

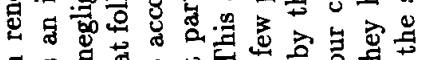

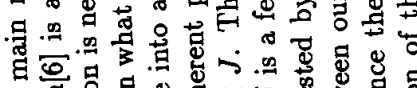

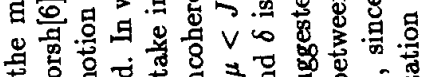

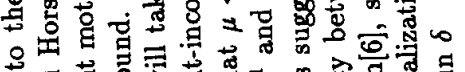

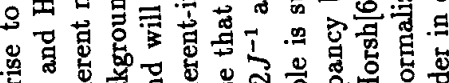

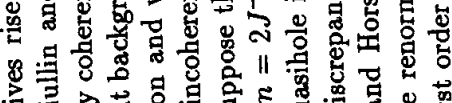

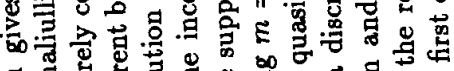

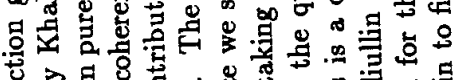

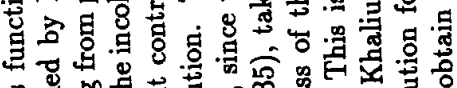

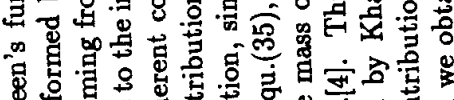

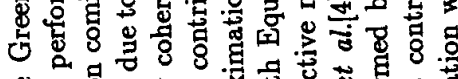

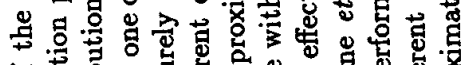

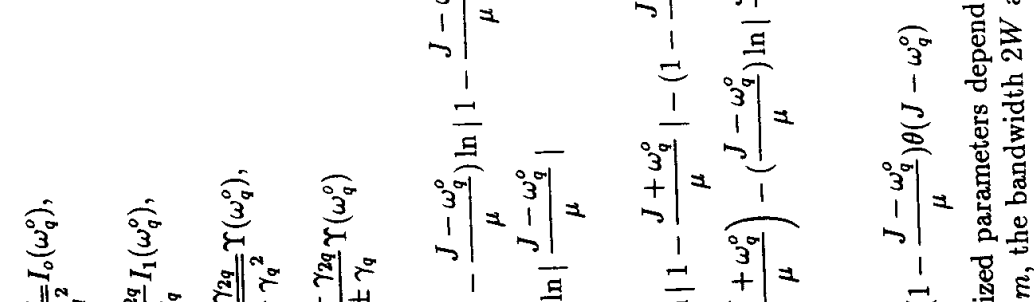

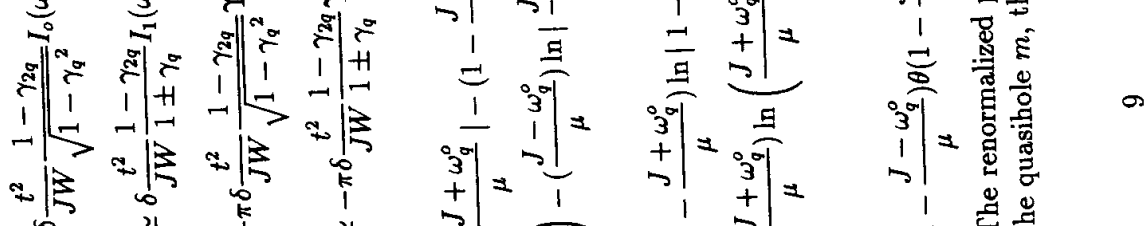

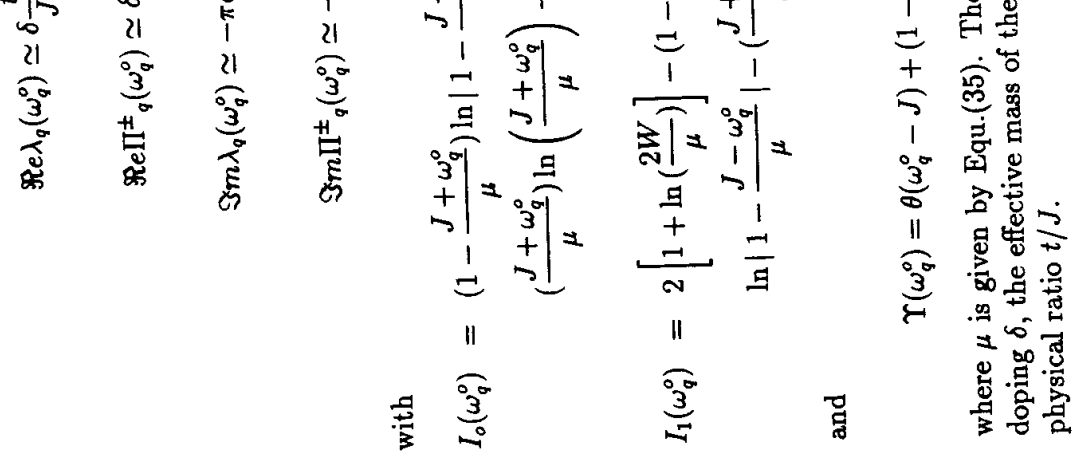

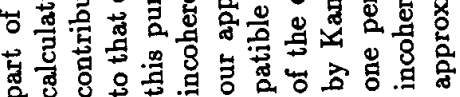

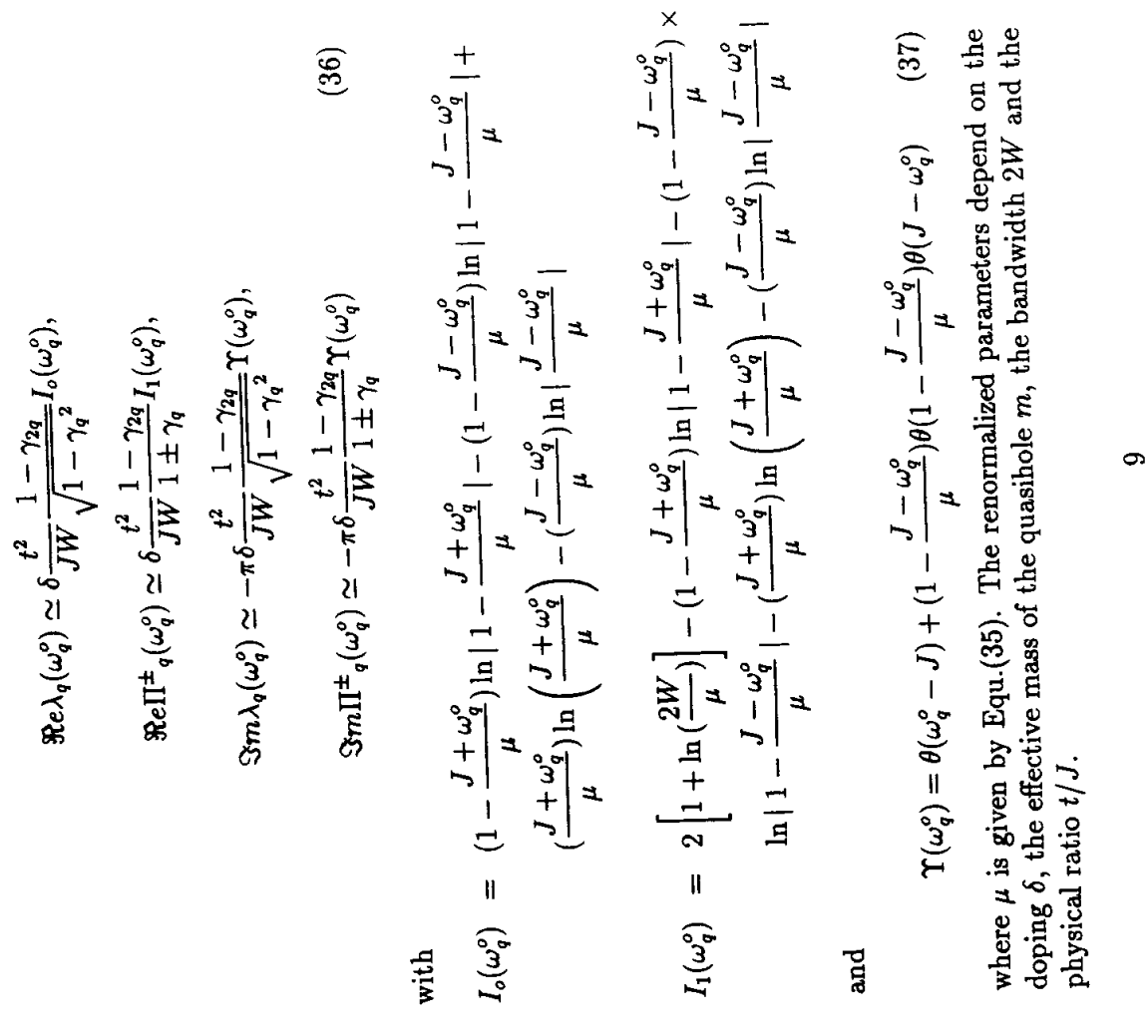

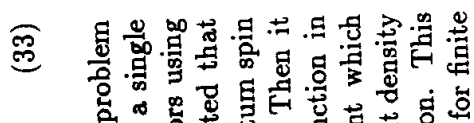

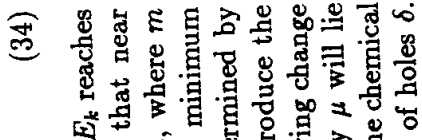

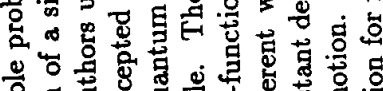

原

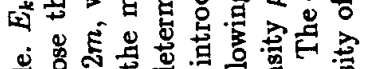

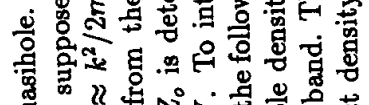

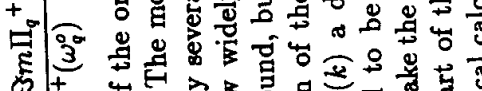

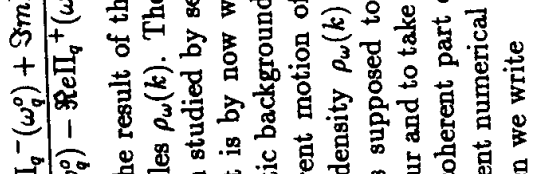

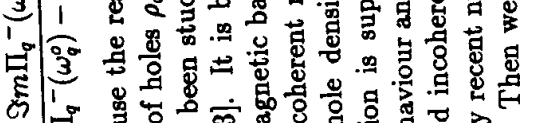
की

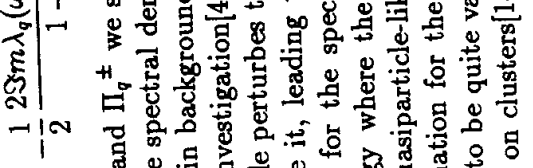
या

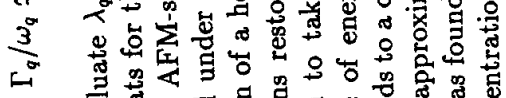

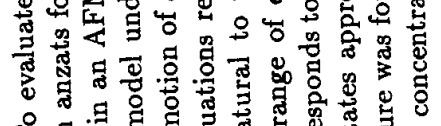



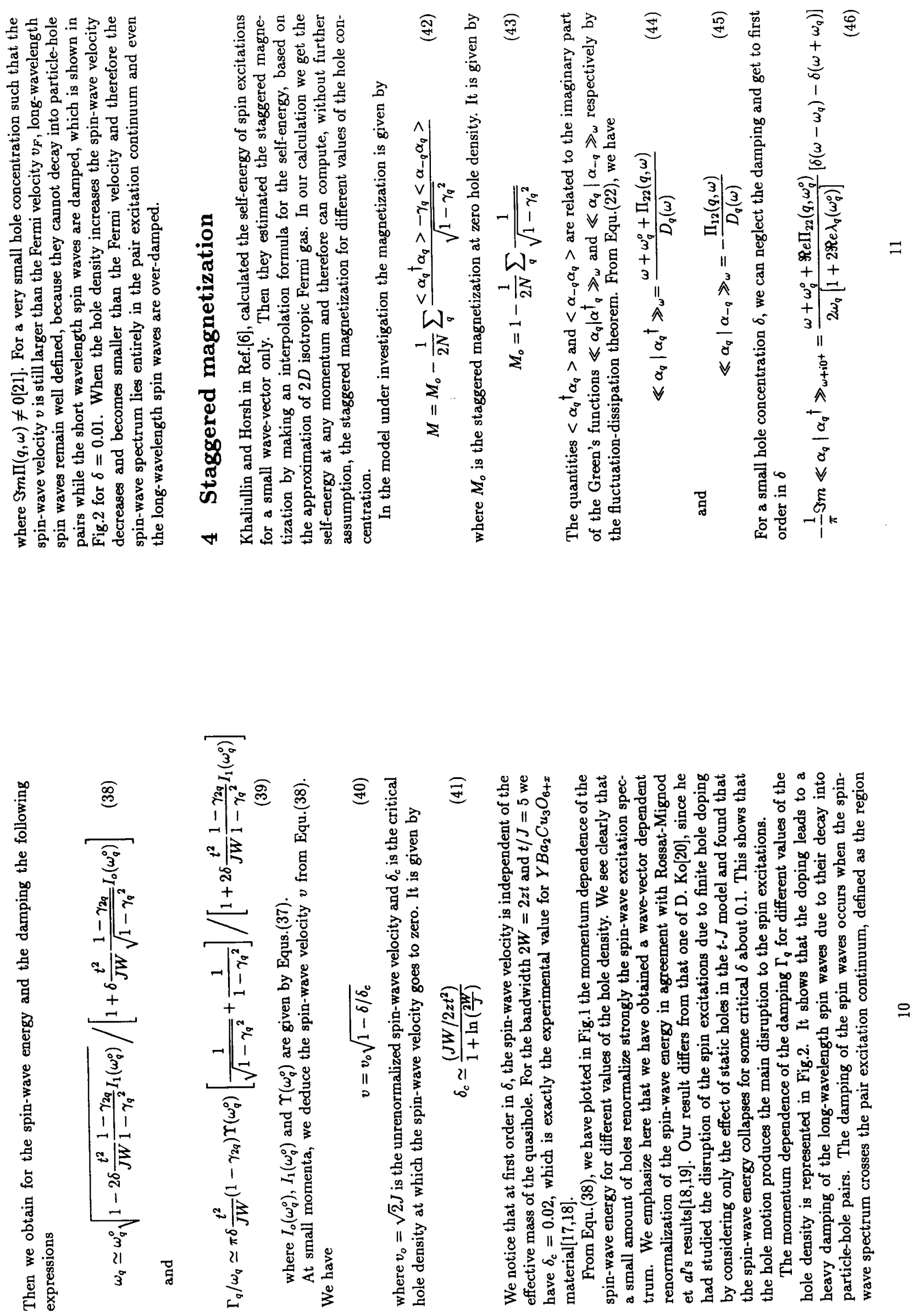


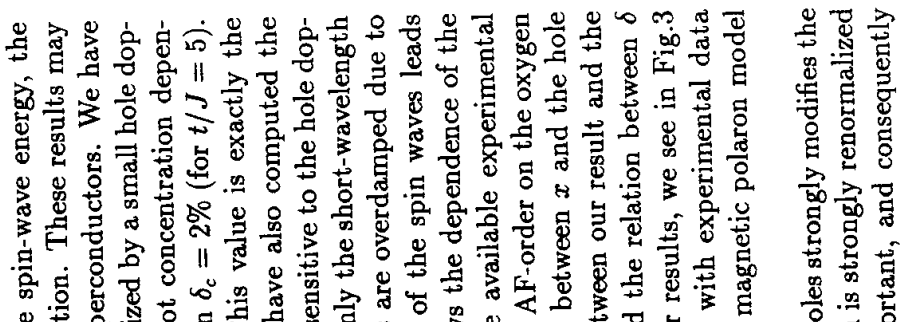

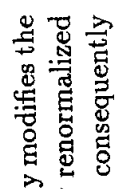

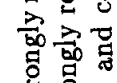

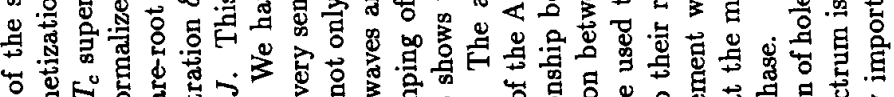

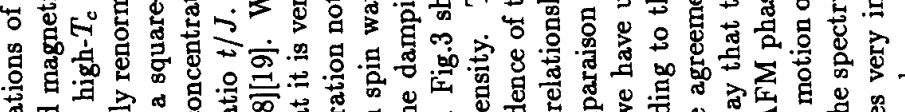

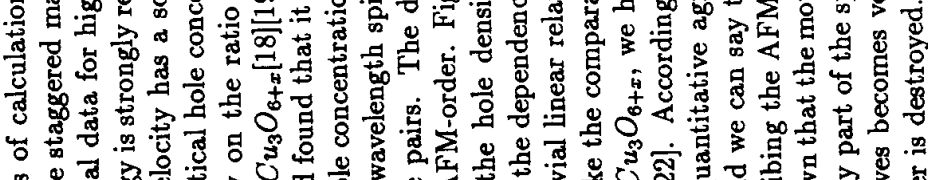
势

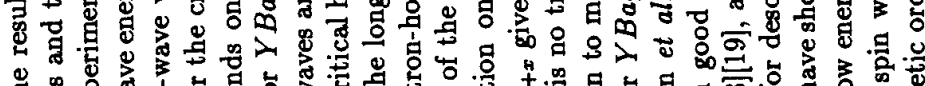

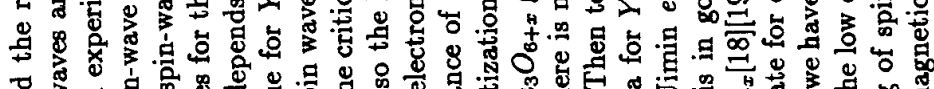

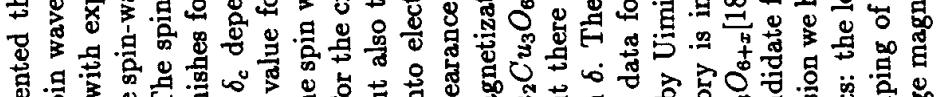

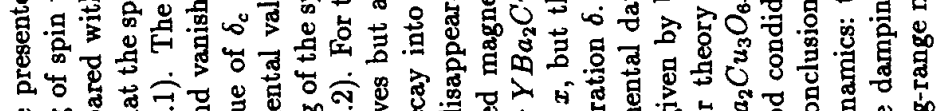

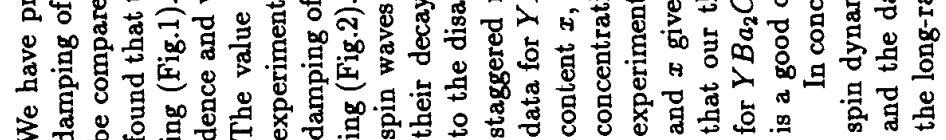
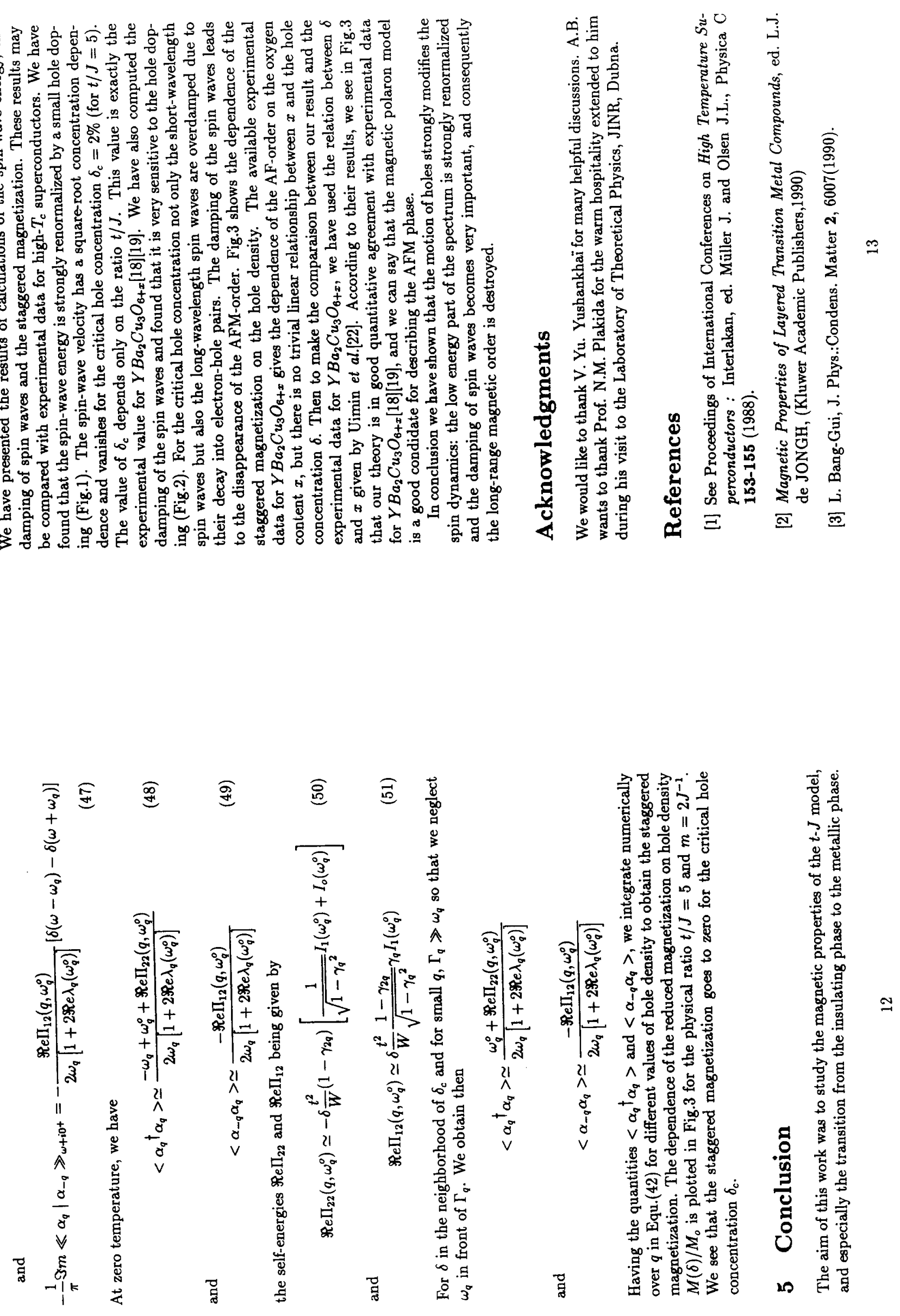

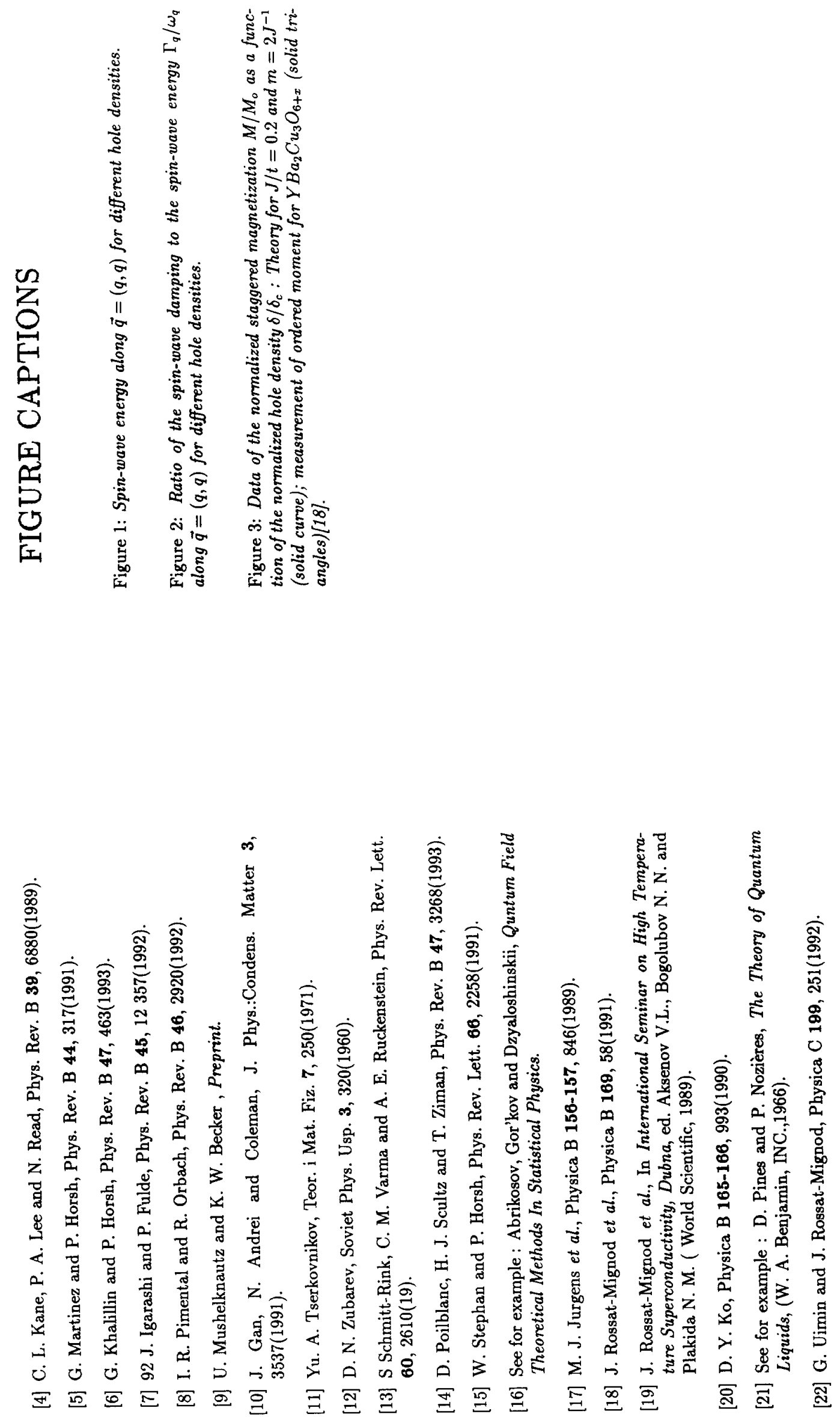